\title{
The Prognostic Significance of Combined Pretreatment Fibrinogen and Neutrophil-Lymphocyte Ratio in Various Cancers: A Systematic Review and Meta-Analysis
}

\author{
Rongqiang Liu $\mathbb{D}^{1,},{ }^{1,2}$ Shiyang Zheng $\mathbb{D},{ }^{3}$ Qing Yuan $\mathbb{D}^{1},{ }^{1}$ Peiwen Zhu $\mathbb{D}^{1},{ }^{1}$ Biao Li $\mathbb{D}^{1},{ }^{1}$ Qi Lin $\left(\mathbb{D},{ }^{1}\right.$

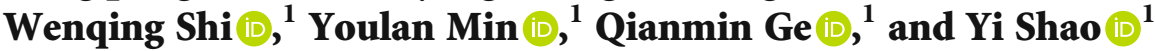 \\ ${ }^{1}$ Department of Ophthalmology, The First Affiliated Hospital of Nanchang University, Nanchang, 330006 Jiangxi, China \\ ${ }^{2}$ Department of Hepatobiliary Surgery, The First Affiliated Hospital of Guangzhou Medical University, Guangzhou, \\ 510220 Guangdong, China \\ ${ }^{3}$ Department of Breast Surgery, The Third Affiliated Hospital of Guangzhou Medical University, Guangzhou 510150, China
}

Correspondence should be addressed to Yi Shao; freebee99@163.com

Received 19 October 2019; Revised 18 April 2020; Accepted 7 October 2020; Published 10 December 2020

Academic Editor: Giorgio Ghigliotti

Copyright (C) 2020 Rongqiang Liu et al. This is an open access article distributed under the Creative Commons Attribution License, which permits unrestricted use, distribution, and reproduction in any medium, provided the original work is properly cited.

\begin{abstract}
Purpose. The prognostic value of a new scoring system, termed F-NLR, that combines pretreatment fibrinogen level with neutrophil-lymphocyte ratio has been evaluated in various cancers. However, the results are controversial. The purpose of this study was to comprehensively analyze the prognostic value of F-NLR score in patients with cancers. Methods. An integrated search of relevant studies was conducted by screening the PubMed and Embase databases. Pooled hazard ratios, with $95 \%$ confidence intervals (CIs), for overall survival (OS) and disease-free survival (DFS)/progression-free survival (PFS) were calculated to estimate the prognostic significance of F-NLR score in patients with various tumors. A random effects model was used for comprehensive analysis, and subgroup and meta-regression analyses were used to explore sources of heterogeneity. Results. Thirteen articles reporting data from of 4747 patients were included in the study. Pooled analysis revealed that high F-NLR score was significantly associated with poor OS $(\mathrm{HR}=1.77$; 95\% CI, 1.51-2.08) and poor DFS/PFS (HR $=1.63 ; 95 \% \mathrm{CI}, 1.30-2.05)$. Subgroup and meta-regression analyses did not alter the prognostic role of F-NLR score in OS and DFS/PFS. Conclusions. Increased F-NLR score is significantly associated with poor prognosis in patients with cancers and can serve as an effective prognostic indicator.
\end{abstract}

\section{Introduction}

Increasing evidence suggests that tumor progression is closely associated with inflammatory responses [1-4]. The systemic proinflammatory effects of tumors are considered to be the result and cause by inhibiting apoptosis and promoting angiogenesis and DNA damage [3]. Numerous inflammatory indices, including the systemic immune inflammation index, platelet/lymphocyte ratio, prognostic nutritional index, modified Glasgow prognostic score, and C-reactive protein/albumin ratio, are closely related to prognosis in patients with cancer [5-10]. Fibrinogen is a $340 \mathrm{kDa}$ glycoprotein synthesized by hepatocytes and has an important role in the coagulation process and can be converted to fibrin by activated thrombin. Fibrinogen can promote tumor cell proliferation, angiogenesis, and hematogenous metastasis, and elevated serum fibrinogen levels are associated with poor prognosis in patients with various tumors [11-16]. The neutrophil-to-lymphocyte ratio (NLR) is another useful marker for assessment of the inflammatory response, which is calculated by dividing the neutrophil count by the lymphocyte count. A number of studies have reported that elevated NLR is associated with poor prognosis in patients with various malignancies, including hepatocellular carcinoma, biliary tract cancer, esophageal cancer, prostate cancer, and colon cancer [17-21]. In recent years, a new scoring system, termed F-NLR, that combines pretreatment fibrinogen levels with NLR has gradually become a hot topic. In general, F-NLR 


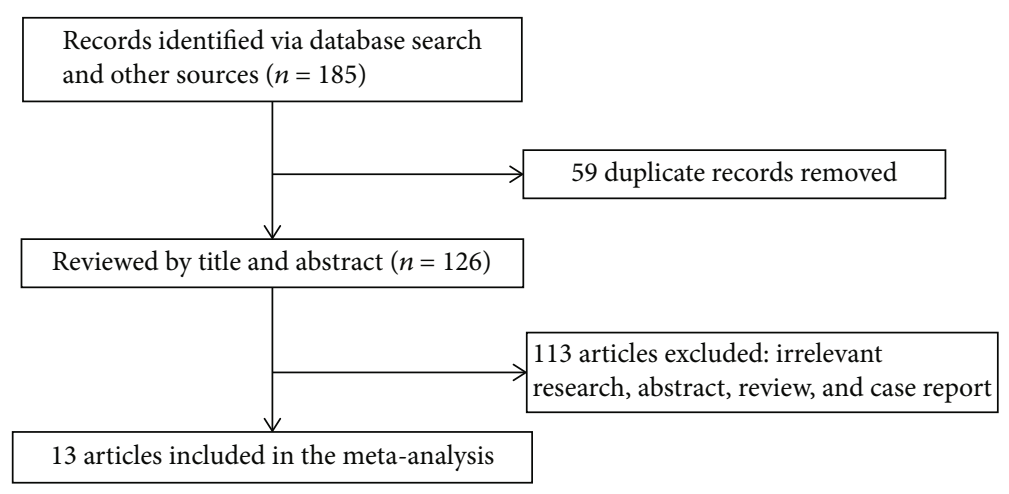

Figure 1: Flow diagram for study screening and selection processes.

score is classified into three groups based on the cutoff value of plasma fibrinogen and NLR, and prognostic situation of patients with cancer is assessed according to different groups. At present, the F-NLR score has been reported as a promising prognostic marker in patients with different types of cancers [22-34]. However, the majority of these studies had small sample sizes; hence, the results are somewhat unreliable and controversial.

Here, we conducted a meta-analysis to comprehensively assess the role of F-NLR score in predicting prognosis in patients with cancer. We also discuss whether F-NLR score is a suitable prognostic marker for patients with cancers.

\section{Materials and Methods}

2.1. Search Strategy. We searched for articles in the PubMed and Embase databases until June 2019, using the keywords "fibrinogen and neutrophil-lymphocyte ratio." Titles, abstracts, full texts, and reference lists were carefully screened to identify objective studies. We searched using keywords, without any restrictions, and manually screened the reference lists in identified publications.

2.2. Study Selection. Articles were considered eligible if they met the following criteria: (1) they investigated associations of F-NLR score with survival outcome in patients with any type of cancer; (2) they provided sufficient data to allow calculation of hazard ratio (HR) and 95\% CI. The exclusion criteria were as follows: (1) they provided insufficient data to allow calculation of $\mathrm{HR}$ and 95\% CI; (2) they were case reports, animal studies, reviews, letters, abstracts, or nonEnglish language publications.

2.3. Data Extraction and Quality Assessment. Two authors extracted the data independently. The relevant information included the first author's name, publication year, country, tumor type, tumor stage, sample size, mean age, analysis type, sex, cutoff value, overall survival (OS), disease-free survival (DFS)/progression-free survival (PFS), hazard ratio, and the corresponding 95\% CI. If a study reported the results of both univariate and multivariate analyses, those from multivariate analysis were selected, as this approach considers confounding factors and is more accurate. Each study was assessed for quality, according to the Newcastle-Ottawa Quality Assess- ment Scale (NOS) [35]. This study does not require the approval of the ethics committee.

2.4. Statistical Analysis. HR and corresponding 95\% CI were used to analyze pooled data. If these statistical variables were described in the study, we used them directly in our analysis; otherwise, data were extracted from graphical survival plots. Data extracted from Kaplan-Meier survival curves were read using Engauge Digitizer version 4.1. A random effects model was used if $I^{2}>50 \%$; otherwise, a fixed-effects model was used. Subgroup analysis and metaregression were used to explore factors contributing to heterogeneity. Publication bias was analyzed by funnel plot. All analyses were performed using STATA version 12.0 software (Stata Corporation, College Station, TX, USA). $P$ values $<0.05$ were considered statistically significant, unless otherwise specified.

\section{Results}

3.1. Study Characteristics. Initial database searching resulted in the retrieval of 185 articles. Titles and abstracts were screened, and abstracts, conference articles, animal experiment studies, and studies reporting incomplete data were excluded. Eventually, 13 articles analyzing the relationship between F-NLR score and outcomes of patients with various cancers were identified. All included articles were published until June 2019. The flow chart for study identification is presented in Figure 1. The total number of patients in the included articles was 4747, with numbers per study ranging from 68 to 1293. In all studies, fibrinogen levels and neutrophil and lymphocyte counts were detected in blood samples. Twelve studies presented OS data and six studies DFS/PFS data. Seven studies were conducted in China, five in Japan, and one in Italy. All studies reported a significant association between high F-NLR score and poor prognosis. The quality of included articles ranged from 6 to 7 (NOS; mean $=6.6$ ). Basic information from all included studies is presented in Table 1.

3.2. F-NLR Score and OS. Twelve studies used OS to describe the relationship between F-score and prognosis. The results of the meta-analysis exhibited moderate heterogeneity $\left(P=0.010, I^{2}=55.3 \%\right)$; therefore, we used a random effects model to calculate the pooled HR $(95 \% \mathrm{CI})$. The results of 
TABLE 1: The basic information of included studies.

\begin{tabular}{|c|c|c|c|c|c|c|c|c|}
\hline Study (year) & Tumor type & Region & $\begin{array}{c}\text { No. of } \\
\text { patients }\end{array}$ & $\begin{array}{c}\text { Age } \\
\text { (mean year) }\end{array}$ & $\begin{array}{c}\text { Cancer stage or } \\
\text { grade }\end{array}$ & Definition of F-NLR score & $\begin{array}{c}\text { End } \\
\text { point }\end{array}$ & $\begin{array}{c}\text { Quality } \\
\text { score }\end{array}$ \\
\hline $\begin{array}{l}\text { Arigami et al. } \\
(2015)\end{array}$ & ESCC & Japan & 238 & 65 & Stage I-III & 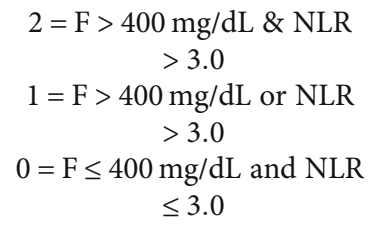 & OS* $^{*}$ & 7 \\
\hline $\begin{array}{l}\text { Arigami et al. } \\
(2016 a)\end{array}$ & GC & Japan & 275 & 66 & Stage I-IV & $\begin{array}{c}2=\mathrm{F}>400 \mathrm{mg} / \mathrm{dL} \& \mathrm{NLR} \\
>3.0 \\
\begin{array}{c}1=\mathrm{F}>400 \mathrm{mg} / \mathrm{dL} \text { or NLR } \\
>3.0 \\
0=\mathrm{F} \leq 400 \mathrm{mg} / \mathrm{dL} \text { and NLR } \\
\leq 3.0\end{array}\end{array}$ & OS* & 7 \\
\hline $\begin{array}{l}\text { Arigami et al. } \\
(2016 b)\end{array}$ & GC & Japan & 68 & 66 & NR & 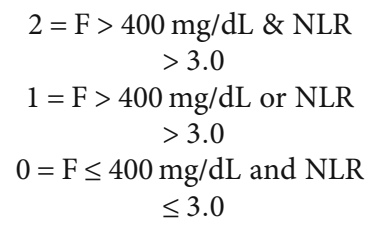 & OS & 6 \\
\hline Fu et al. (2017) & HCC & China & 130 & 49.5 & NR & $\begin{array}{c}2=\mathrm{F}>234.5 \mathrm{mg} / \mathrm{dL} \& \mathrm{NLR} \\
>1.84 \\
1=\mathrm{F}>234.5 \mathrm{mg} / \mathrm{dL} \text { or } \\
\mathrm{NLR}>1.84 \\
0=\mathrm{F} \leq 234.5 \mathrm{mg} / \mathrm{dL} \text { and } \\
\mathrm{NLR} \leq 1.84\end{array}$ & OS, DFS & 6 \\
\hline Hao et al. (2019) & Glioblastoma & China & 187 & 55 & NR & $\begin{array}{c}2=\mathrm{F}>340 \mathrm{mg} / \mathrm{dL} \& \mathrm{NLR} \\
>4.1 \\
\begin{array}{c}1=\mathrm{F}>340 \mathrm{mg} / \mathrm{dL} \text { or NLR } \\
>4.1 \\
0=\mathrm{F} \leq 340 \mathrm{mg} / \mathrm{dL} \text { and NLR } \\
\leq 4.1\end{array}\end{array}$ & OS* & 7 \\
\hline $\begin{array}{l}\text { Huang et al. } \\
(2018)\end{array}$ & NSCLC & China & 589 & 60 & Stage I-IIIA & 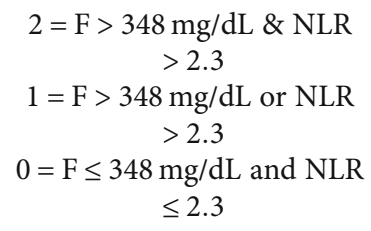 & $\begin{array}{l}\text { OS*, } \\
\text { DFS* }\end{array}$ & 7 \\
\hline $\begin{array}{l}\text { Kijima et al. } \\
(2017)\end{array}$ & ESCC & Japan & 98 & 64.9 & Stage III-IV & $\begin{array}{c}2=\mathrm{F}>400 \mathrm{mg} / \mathrm{dL} \& \mathrm{NLR} \\
>3.0 \\
\begin{array}{c}1=\mathrm{F}>400 \mathrm{mg} / \mathrm{dL} \text { or NLR } \\
>3.0 \\
0=\mathrm{F} \leq 400 \mathrm{mg} / \mathrm{dL} \text { and NLR } \\
\leq 3.0\end{array}\end{array}$ & OS* $^{*}$ & 7 \\
\hline $\begin{array}{l}\text { Kuwahara et al. } \\
(2018)\end{array}$ & HPC & Japan & 111 & 67 & Stage III-IV & $\begin{array}{c}2=\mathrm{F}>341 \mathrm{mg} / \mathrm{dL} \& \mathrm{NLR} \\
>3.59 \\
1=\mathrm{F}>341 \mathrm{mg} / \mathrm{dL} \text { or NLR } \\
>3.59 \\
0=\mathrm{F} \leq 341 \mathrm{mg} / \mathrm{dL} \text { and NLR } \\
\leq 3.59\end{array}$ & OS, PFS & 7 \\
\hline Li et al. (2018) & CRC & China & 693 & NR & Stage I-III & $\begin{array}{c}2=\mathrm{F}>297 \mathrm{mg} / \mathrm{dL} \& \mathrm{NLR} \\
>2.34 \\
1=\mathrm{F}>297 \mathrm{mg} / \mathrm{dL} \text { or NLR } \\
>2.34 \\
0=\mathrm{F} \leq 297 \mathrm{mg} / \mathrm{dL} \text { and NLR } \\
\leq 2.34\end{array}$ & OS, DFS & 6 \\
\hline
\end{tabular}


TABLE 1: Continued.

\begin{tabular}{|c|c|c|c|c|c|c|c|c|}
\hline Study (year) & Tumor type & Region & $\begin{array}{c}\text { No. of } \\
\text { patients }\end{array}$ & $\begin{array}{c}\text { Age } \\
\text { (mean year) }\end{array}$ & $\begin{array}{c}\text { Cancer stage or } \\
\text { grade }\end{array}$ & Definition of F-NLR score & $\begin{array}{c}\text { End } \\
\text { point }\end{array}$ & $\begin{array}{l}\text { Quality } \\
\text { score }\end{array}$ \\
\hline $\begin{array}{l}\text { Liang et al. } \\
(2019)\end{array}$ & NSCLC & China & 456 & 61 & Stage I-IIIA & $\begin{array}{c}2=\mathrm{F}>377 \mathrm{mg} / \mathrm{dL} \& \mathrm{NLR} \\
>2.28 \\
1=\mathrm{F}>377 \mathrm{mg} / \mathrm{dL} \text { or NLR } \\
>2.28 \\
0=\mathrm{F} \leq 377 \mathrm{mg} / \mathrm{dL} \text { and NLR } \\
\leq 2.28\end{array}$ & OS & 6 \\
\hline Liu et al. (2018) & GC & China & 1293 & 59 & Stage I-III & $\begin{array}{c}2=\mathrm{F}>400 \mathrm{mg} / \mathrm{dL} \& \mathrm{NLR} \\
>5.0 \\
\begin{array}{c}1=\mathrm{F}>400 \mathrm{mg} / \mathrm{dL} \text { or NLR } \\
>5.0 \\
0=\mathrm{F} \leq 400 \mathrm{mg} / \mathrm{dL} \text { and NLR } \\
\leq 5.0\end{array}\end{array}$ & OS* $^{*}$ & 7 \\
\hline $\begin{array}{l}\text { Marchetti et al. } \\
\text { (2018) }\end{array}$ & $\mathrm{OC}$ & Italy & 94 & 55 & Stage I-IV & $\begin{array}{c}2=\mathrm{F}>450 \mathrm{mg} / \mathrm{dL} \& \mathrm{NLR} \\
>3.24 \\
1=\mathrm{F}>450 \mathrm{mg} / \mathrm{dL} \text { or NLR } \\
>3.24 \\
0=\mathrm{F} \leq 450 \mathrm{mg} / \mathrm{dL} \text { and NLR } \\
\leq 3.24\end{array}$ & PFS & 6 \\
\hline $\begin{array}{l}\text { Wang et al. } \\
(2018)\end{array}$ & NSCLC & China & 515 & 60.4 & Stage I-IIIA & $\begin{array}{c}2=\mathrm{F}>338 \mathrm{mg} / \mathrm{dL} \& \mathrm{NLR} \\
>2.21 \\
1=\mathrm{F}>338 \mathrm{mg} / \mathrm{dL} \text { or NLR } \\
>2.21 \\
0=\mathrm{F} \leq 338 \mathrm{mg} / \mathrm{dL} \text { and NLR } \\
\leq 2.21\end{array}$ & $\begin{array}{l}\text { OS*, } \\
\text { DFS* }\end{array}$ & 7 \\
\hline
\end{tabular}

ESCC: esophageal squamous cell carcinoma; GC: gastric cancer; HCC: hepatocellular carcinoma; NSCLC: non-small-cell lung cancer; HPC: hypopharyngeal carcinoma; CRC: colorectal adenocarcinoma; OC: ovarian cancer; OS: overall survival; DFS: disease-free survival; PFS: progression-free survival; ${ }^{*}$ multivariate analysis.

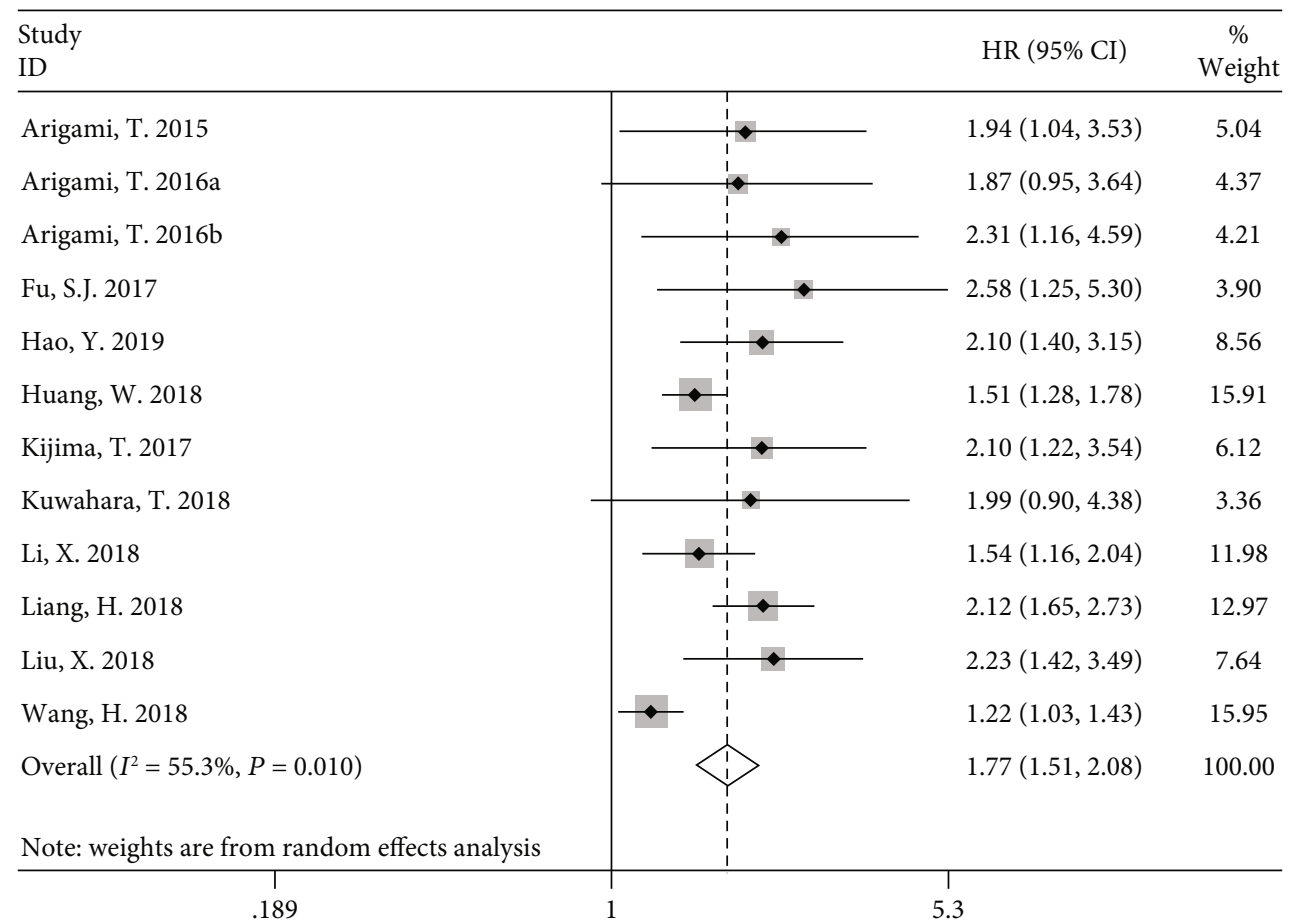

FIGURE 2: Forest plot of the relationship between F-score and OS. 


\begin{tabular}{|c|c|c|c|}
\hline $\begin{array}{l}\text { Study } \\
\text { ID } \\
\end{array}$ & & HR $(95 \%$ CI $)$ & $\begin{array}{c}\% \\
\text { Weight } \\
\end{array}$ \\
\hline Fu, S.J. 2017 & & $-3.26(1.91,5.57)$ & 10.54 \\
\hline Huang, W. 2018 & $\rightarrow \frac{1}{1}$ & $1.47(1.24,1.73)$ & 22.39 \\
\hline Kuwahara, T. 2018 & & $1.65(0.97,2.81)$ & 10.62 \\
\hline Li, X. 2018 & 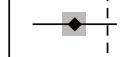 & $1.38(1.11,1.71)$ & 20.65 \\
\hline Marchetti, C. 2018 & & $2.49(1.44,3.41)$ & 13.27 \\
\hline Wang, H. 2018 & 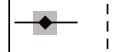 & $1.19(1.01,1.40)$ & 22.52 \\
\hline Overall $\left(I^{2}=76.1 \%, P=0.001\right)$ & & $1.63(1.30,2.05)$ & 100.00 \\
\hline Note: weights are from random effects analysis & & & \\
\hline .18 & & & \\
\hline
\end{tabular}

FIGURE 3: Forest plot of the relationship between F-score and DFS/PFS.

TABLE 2: Subgroup analysis and metaregression of the studies reporting the effect of F-NLR score in OS.

\begin{tabular}{|c|c|c|c|c|c|c|c|}
\hline \multirow[b]{2}{*}{ Stratified study } & \multirow[b]{2}{*}{ No. of studies } & \multirow[b]{2}{*}{ Pooled HR (95\% CI) } & \multicolumn{2}{|c|}{ Heterogeneity } & \multicolumn{3}{|c|}{ Metaregression } \\
\hline & & & $I^{2}(\%)$ & $P$ value & $\mathrm{Tau}^{2}$ & $\operatorname{Adj} R^{2}(\%)$ & $P$ value \\
\hline Cancer type & & & & & 0.04 & -11.81 & 0.77 \\
\hline Digestive system & 7 & $1.817(1.497-2.206)$ & 0 & 0.77 & & & \\
\hline NSCLC & 4 & $1.65(1.266-2.15)$ & 81.9 & $<0.01$ & & & \\
\hline Other type & 1 & $2.103(1.401-3.156)$ & - & - & & & \\
\hline Publication year & & & & & 0.03 & 15.36 & 0.23 \\
\hline$\geq 2017$ & 7 & $1.683(1.389-2.04)$ & 69.3 & $<0.01$ & & & \\
\hline$<2017$ & 5 & $2.121(1.598-2.817)$ & 0 & 0.97 & & & \\
\hline Sample size & & & & & 0.03 & 29.73 & 0.11 \\
\hline$n \leq 390$ & 7 & $2.105(1.684-2.631)$ & 0 & 0.99 & & & \\
\hline$n>390$ & 5 & $1.618(1.307-2.004)$ & 76 & $<0.01$ & & & \\
\hline Country & & & & & 0.03 & 8.8 & 0.36 \\
\hline China & 7 & $1.715(1.406-2.092)$ & 71.6 & $<0.01$ & & & \\
\hline Japan & 5 & $2.04(1.531-2.718)$ & 0 & 0.99 & & & \\
\hline Analysis type & & & & & 0.03 & 6.9 & 0.37 \\
\hline Multivariate & 7 & $1.676(1.371-2.049)$ & 58.9 & 0.02 & & & \\
\hline Univariate & 5 & $1.909(1.608-2.267)$ & 0 & 0.43 & & & \\
\hline Gender (Female, \%) & & & & & 0.02 & 44.22 & 0.1 \\
\hline$>31$ & 7 & $1.617(1.35-1.937)$ & 56.7 & 0.03 & & & \\
\hline$\leq 31$ & 5 & $2.12(1.739-2.585)$ & 0 & 0.98 & & & \\
\hline Age (year) & & & & & 0.04 & -12.82 & 0.61 \\
\hline$>60$ & 8 & $1.742(1.389-2.184)$ & 61.4 & 0.01 & & & \\
\hline$\leq 60$ & 4 & $1.874(1.445-2.432)$ & 46.7 & 0.13 & & & \\
\hline
\end{tabular}

meta-analysis revealed that high F-NLR score was significantly associated with poor OS, with a pooled HR of 1.77 (95\% CI, 1.51-2.08) (Figure 2).
3.3. F-NLR Score and DFS/PFS. Six studies also reported DFS/PFS data to document the relationship between Fscore and prognosis. We used a random effects model to 
TABLE 3: Subgroup analysis and metaregression of the studies reporting the prognostic role of F-NLR score in DFS/PFS.

\begin{tabular}{|c|c|c|c|c|c|c|c|}
\hline \multirow{2}{*}{ Stratified study } & \multirow{2}{*}{ No. of studies } & \multirow{2}{*}{ Pooled HR (95\% CI) } & \multicolumn{2}{|c|}{ Heterogeneity } & \multicolumn{3}{|c|}{ Metaregression } \\
\hline & & & $I^{2}(\%)$ & $P$ value & $\mathrm{Tau}^{2}$ & $\operatorname{Adj} R^{2}(\%)$ & $P$ value \\
\hline Cancer type & & & & & 0.13 & -35.24 & 0.9 \\
\hline Digestive system & 3 & $1.875(1.133-3.102)$ & 76.6 & 0.01 & & & \\
\hline NSCLC & 2 & $1.32(1.076-1.619)$ & 68.1 & 0.08 & & & \\
\hline Other type & 1 & $2.49(1.618-3.832)$ & - & - & & & \\
\hline Publication year & & & & & 0.04 & 63.11 & 0.1 \\
\hline$\geq 2017$ & 5 & $1.471(1.22-1.773)$ & 64.9 & 0.02 & & & \\
\hline$<2017$ & 1 & $3.26(1.909-5.567)$ & - & - & & & \\
\hline Sample size & & & & & 0.01 & 93.11 & 0.03 \\
\hline$n \leq 390$ & 3 & $2.383(1.659-3.422)$ & 37.3 & 0.2 & & & \\
\hline$n>390$ & 3 & $1.334(1.169-1.523)$ & 39 & 0.19 & & & \\
\hline Country & & & & & 0.07 & 25.86 & 0.34 \\
\hline China & 4 & $1.497(1.182-1.896)$ & 71.6 & $<0.01$ & & & \\
\hline Japan & 1 & $1.65(0.969-2.808)$ & - & - & & & \\
\hline Italy & 1 & $2.49(1.618-3.832)$ & - & - & & & \\
\hline Analysis type & & & & & 0.07 & 21.85 & 0.21 \\
\hline Multivariate & 2 & $1.32(1.076-1.619)$ & 68.1 & 0.08 & & & \\
\hline Univariate & 4 & $2.005(1.327-3.031)$ & 75.6 & $<0.01$ & & & \\
\hline Gender (female, \%) & & & & & 0.06 & 33.39 & 0.25 \\
\hline$>31$ & 4 & $1.46(1.189-1.793)$ & 72.6 & 0.01 & & & \\
\hline$\leq 31$ & 2 & $2.318(1.189-4.517)$ & 68 & 0.08 & & & \\
\hline Age (year) & & & & & 0.06 & 30.42 & 0.16 \\
\hline$>60$ & 3 & $1.278(1.12-1.459)$ & 82.9 & $<0.01$ & & & \\
\hline$\leq 60$ & 3 & $2.181(1.304-3.646)$ & 5.8 & 0.34 & & & \\
\hline
\end{tabular}

calculate pooled HR (95\% CI) values, based on the detection of clear heterogeneity among the six studies $(P=0.001$, $\left.I^{2}=76.1 \%\right)$. The results showed that high F-NLR score was significantly associated with poor DFS/PFS, with a pooled HR of 1.63 (95\% CI, 1.30-2.05) (Figure 3).

3.4. Subgroup and Metaregression Analyses. Given the existence of significant heterogeneity among the studies, we performed subgroup and regression analyses according to tumor type, publication year, sample size, country, analysis type, sex, and mean age. Subgroup and metaregression analyses did not alter the prognostic role of F-NLR score in OS and DFS/PFS. We noted slighter heterogeneity in stratified studies according to digestive system tumor, publication year $(<2017)$, sample size $(\leq 390)$, country (Japan), univariate analysis, or sex (female $\leq 31 \%$ ) in OS (Table 2). Similarly, we observed no heterogeneity in stratified studies according to age $(\leq 60)$ and minor heterogeneity in stratified studies with sample size in DFS/PFS (Table 3).

3.5. Sensitivity Analysis and Publication Bias. Sensitivity analysis was conducted by removing each study from the combined dataset sequentially. As shown in Figure 4, the results did not differ significantly from the overall analysis, indicating that the outcome was stable. Further, we used funnel plots to evaluate publication bias using total OS or DFS/PFS data. Begg's test and Egger's test were applied to provide statistical evidence for funnel plot symmetry. As shown in Figure 5, Begg's test and Egger's test $P$ values were 0.537 and 0.01 for OS and 0.06 and 0.047 for DFS/PFS, indicating there existed publication bias for either type of report. However, the trimand-fill method displayed that the pooled HR for OS was 1.47 (95\% CI: $1.263-1.732$ ) and 1.58 (95\% CI: 1.187-1.916) for DFS/PFS, which further confirmed the results were not affected.

\section{Discussion}

The F-NLR score, based on fibrinogen levels and neutrophil and lymphocyte counts, represents inflammatory responses and the cancer microenvironment. Fibrinogen, an acutephase response protein, is primarily synthesized in the liver but can also be produced by tumor cells [36]. In particular, tumor cells can promote fibrinogen secretion by producing interleukin-6 [37]. When stimulated with inflammatory factors or by tumors, activated thrombin can transform fibrinogen into fibrin, which can form a stable framework and extracellular matrix around tumor cells, preventing tumor cell killing by immune cells [38]. Further, in vivo tumor metastasis is remarkably diminished in fibrinogen-deficient mice [39]. Neutrophils can promote tumor invasion, metastasis, and angiogenesis by producing various cytokines, such as tumor necrosis factor-alpha, vascular endothelial growth factor, fibroblast growth factor, angiopoietin, and interleukin 


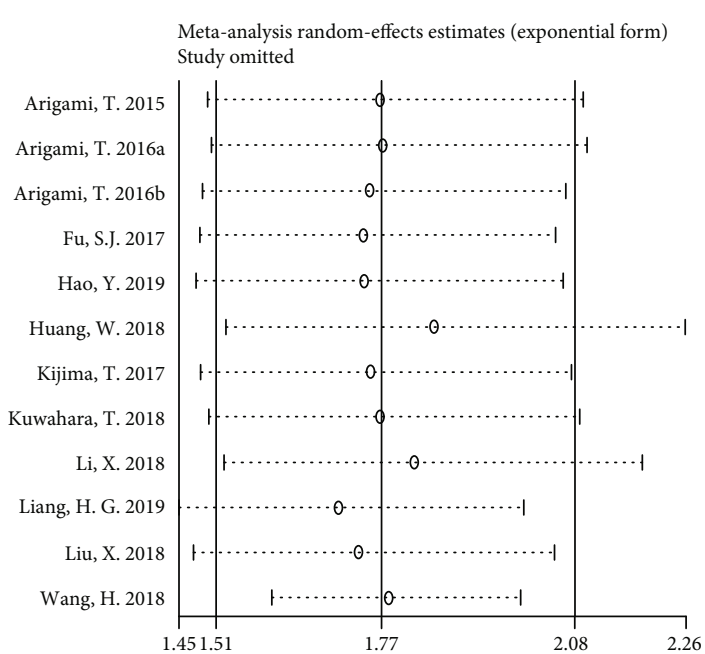

(a)

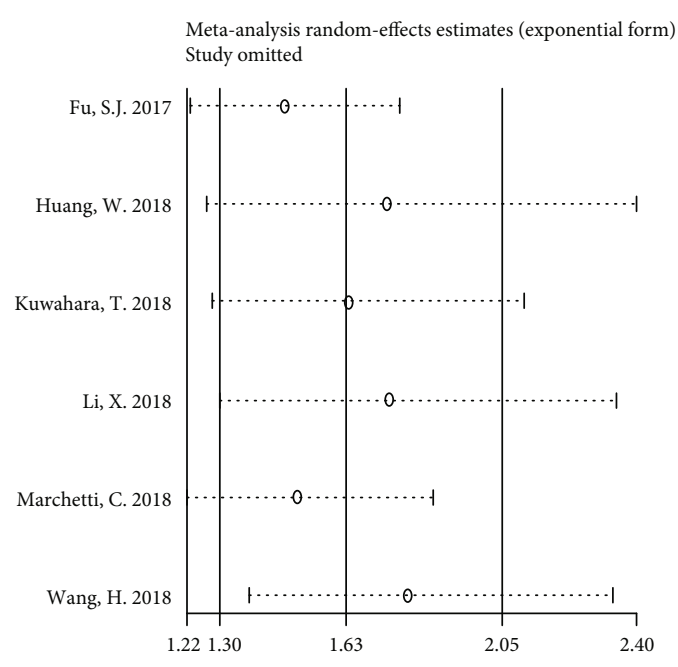

(b)

FIGURE 4: Funnel plot of sensitivity analysis. (a) Sensitivity analysis for OS. (b) Sensitivity analysis for DFS/PFS.
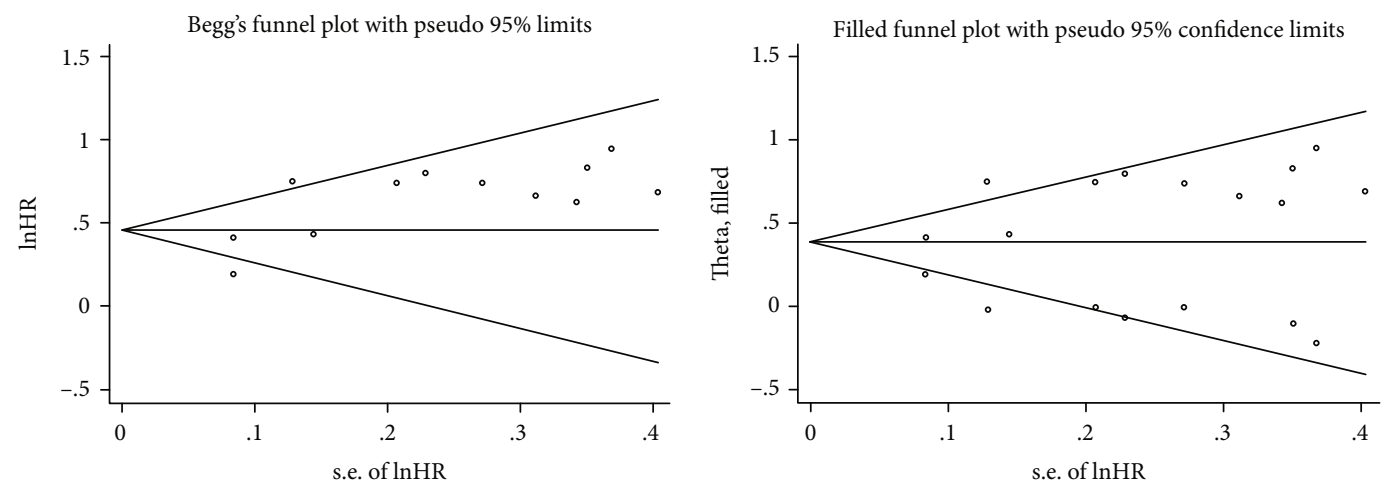

(a)
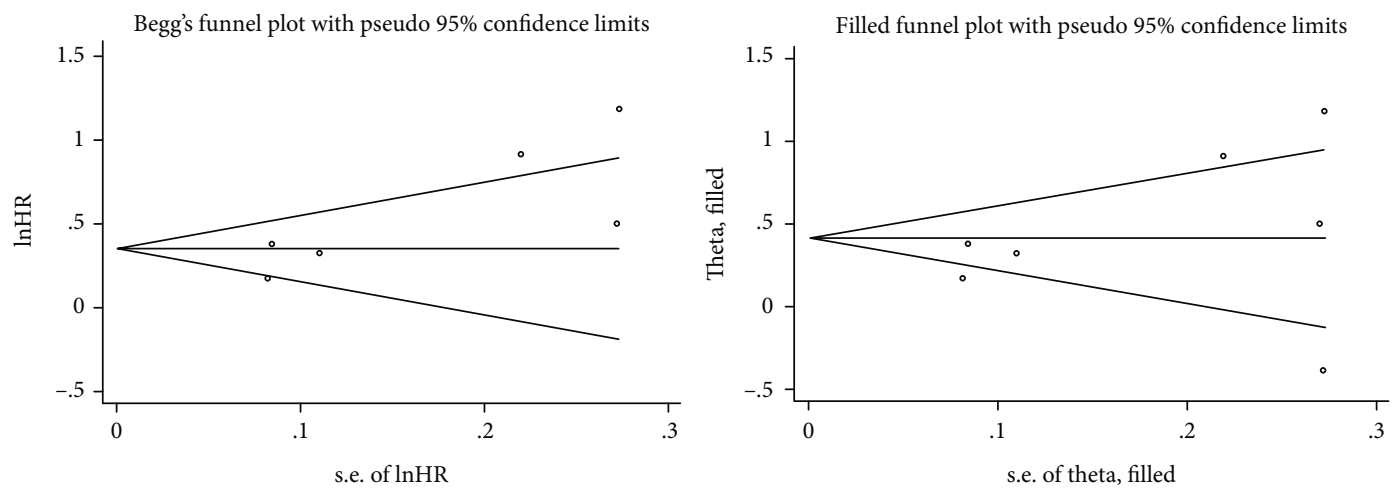

(b)

FIgURE 5: Funnel plots for publication bias. (a) Funnel plots without and with trim and fill to evaluate OS data. (b) Funnel plots without and with trim and fill to evaluate DFS/PFS data.

[40, 41]. Neutrophils can also promote tumor cell metastasis by secreting neutrophil extracellular traps [42]. In addition, elevated neutrophil numbers can prevent other immune cells from killing tumor cells, and high levels of tumor-infiltrating neutrophils are an indicator of poor prognosis in gastric can- cer [43]. Lymphocytes have important roles in antitumor immune defense, and lymphocyte reduction can be considered an immune deficiency, in terms of antitumor immune responses. Lymphocytes can promote tumor cell apoptosis and produce cytokines to inhibit tumor cell proliferation 
and metastasis $[44,45]$. A previous study reported that lymphopenia is associated with poor prognosis [46]. Studies have confirmed that fibrinogen or NLR can present a good prognostic indicator for patients with cancer. However, fibrinogen or NLR alone may emerge a limited effect on tumor progression. F-NLR score overcomes the unfavorable effect of fibrinogen and NLR and effectively improves the predicted value for patients with cancers.

Liu et al. analyzed 1293 consecutive patients who underwent curative surgery for gastric cancer. They found that higher F-NLR scores were associated with larger tumor size, deeper tumor invasion, and more lymph node metastasis and were independently prognostic predictor [32]. Similarly, Arigami et al. revealed that the F-NLR score correlated with the depth of tumor invasion, lymph node metastasis, lymphatic vessel invasion, tumor size, and stage and was an independent prognostic factor for esophageal squamous cell carcinoma [22]. Wang et al. disclosed that the 5-year DFS rates in F-NLR groups 0,1 , and 2 were $46.7 \%, 36.4 \%$, and $30.1 \%$ and the 5 -year overall survival (OS) rates in the above three groups were $52.0 \%, 39.8 \%$, and $32.1 \%$, respectively. They thought that lung cancer patients with a high-risk preoperative F-NLR group scores may benefit from adjuvant therapy by subgroup analysis [34]. Li et al. showed that an elevated F-NLR score was significantly associated with worse OS and DFS in patients with colorectal adenocarcinoma. They also found that DFS in a low F-NLR score group was significantly shortened after chemotherapy, and patients with a relatively high F-NLR score group showed a slight OS benefit from adjuvant chemotherapy [30].

To the best of our knowledge, this study is the first metaanalysis to comprehensively explore the prognostic value of F-NLR score in various tumors. Our meta-analysis demonstrates that high F-NLR score is significantly associated with poor OS, with a pooled HR of 1.77 (95\% CI, 1.51-2.08) and poor DFS/PFS (HR $=1.63$; 95\% CI, 1.30-2.05). Subgroup and metaregression analyses revealed that tumor type, publication year, sample size, country, analysis type, and sex may be sources of heterogeneity in OS, and sample size and age contributed to the heterogeneity in DFS/PFS. Sensitivity analysis and the trim-and-fill method showed that the pooled results were stable.

Our meta-analysis has limitations. First, all included articles were from studies with small sample sizes; hence, their results may be somewhat unreliable. Second, the research methods and cutoff values used in included studies differed from one another, which influences judgment of F-NLR score as a prognostic marker. Third, the majority of studies included in the meta-analysis were conducted in three countries, which may affect the reliability of our results. Fourth, we acknowledged that there existed the flaw that only two database engines were used to retrieve data. Fifth, extracting HR and 95\% CI from the survival curve may bring slight error. Finally, due to the lack of the additional clinicopathological parameters of selected articles, we cannot assess the relationship between F-NLR scores and other clinicopathological parameters.

In conclusion, our meta-analysis demonstrates that increased F-NLR score is significantly associated with poor prognosis in patients with cancer and that F-NLR score can be used as an effective prognostic indicator. However, considering the limitations of this study, further large-scale, well-designed, and multicenter prospective researches are needed to validate our results before the application of F-NLR score for the prognosis of various cancers.

\section{Data Availability}

All data are in the manuscript and can be obtained from the corresponding author.

\section{Conflicts of Interest}

The authors deny any conflict of interest.

\section{Authors' Contributions}

Rongqiang Liu and Shiyang Zheng have contributed equally to this work.

\section{Acknowledgments}

This work was supported by grants from the National Natural Science Foundation of China (No. 81660158), Natural Science Key Project of Jiangxi Province (No. 20161ACB21017), and Youth Science Foundation of Jiangxi Province (Nos. 20151BAB215016 and 20161BAB215198).

\section{References}

[1] M. Tarocchi, S. Polvani, G. Marroncini, and A. Galli, "Molecular mechanism of hepatitis B virus-induced hepatocarcinogenesis," World Journal of Gastroenterology, vol. 20, no. 33, pp. 11630-11640, 2014.

[2] D. Hanahan and R. A. Weinberg, "Hallmarks of cancer: the next generation," Cell, vol. 144, no. 5, pp. 646-674, 2011.

[3] C. I. Diakos, K. A. Charles, D. C. McMillan, and S. J. Clarke, "Cancer-related inflammation and treatment effectiveness," The Lancet Oncology, vol. 15, no. 11, pp. e493-e503, 2014.

[4] L. M. Coussen and Z. Werb, "Inflammation and cancer," Nature, vol. 420, no. 6917, pp. 860-867, 2002.

[5] J. H. Chen, E. T. Zhai, Y. J. Yuan et al., "Systemic immuneinflammation index for predicting prognosis of colorectal cancer," World Journal of Gastroenterology, vol. 23, no. 34, pp. 6261-6272, 2017.

[6] Y. Hu, J. Shen, R. K. Liu et al., "Prognostic value of pretreatment prognostic nutritional index in non-small cell lung cancer: a systematic review and meta-analysis," The International Journal of Biological Markers, vol. 33, no. 4, pp. 372-378, 2018.

[7] H. Chen, N. Hu, P. Chang et al., "Modified Glasgow prognostic score might be a prognostic factor for hepatocellular carcinoma: a meta-analysis," Panminerva Medica, vol. 59, no. 4, pp. 302-307, 2017.

[8] F. Sun, X. Ge, Z. Liu, S. Du, S. Ai, and W. Guan, "Postoperative C-reactive protein/albumin ratio as a novel predictor for short-term complications following gastrectomy of gastric cancer," World Journal of Surgical Oncology, vol. 15, no. 1, p. 191, 2017.

[9] S. Ozmen, O. Timur, I. Calik et al., "Neutrophil-lymphocyte ratio (NLR) and platelet-lymphocyte ratio (PLR) may be 
superior to C-reactive protein (CRP) for predicting the occurrence of differentiated thyroid cancer," Endocrine Regulations, vol. 51, no. 3, pp. 131-136, 2017.

[10] W. Song, C. Tian, K. Wang, R. J. Zhang, and S. B. Zou, "Preoperative platelet lymphocyte ratio as independent predictors of prognosis in pancreatic cancer: a systematic review and meta-analysis," PLoS One, vol. 12, no. 6, article e0178762, 2017.

[11] L. Sheng, M. Luo, X. Sun, N. Lin, W. Mao, and D. Su, "Serum fibrinogen is an independent prognostic factor in operable nonsmall cell lung cancer," International Journal of Cancer, vol. 133, no. 11, pp. 2720-2725, 2013.

[12] G. Huang, H. Jiang, Y. Lin et al., "Prognostic value of plasma fibrinogen in hepatocellular carcinoma: a meta-analysis," Cancer Management and Research, vol. 10, pp. 5027-5041, 2018.

[13] H. Xu, J. Z. Ai, P. Tan et al., "Pretreatment elevated fibrinogen level predicts worse oncologic outcomes in upper tract urothelial carcinoma," Asian Journal of Andrology, vol. 22, no. 2, pp. 177-183, 2020.

[14] H. X. Cai, X. Q. Li, and S. F. Wang, "Prognostic value of fibrinogen and D-dimer-fibrinogen ratio in resectable gastrointestinal stromal tumors," World Journal of Gastroenterology, vol. 24, no. 44, pp. 5046-5056, 2018.

[15] H. Takeuchi, S. Ikeuchi, Y. Kitagawa et al., "Pretreatment plasma fibrinogen level correlates with tumor progression and metastasis in patients with squamous cell carcinoma of the esophagus," Journal of Gastroenterology and Hepatology, vol. 22, no. 12, pp. 2222-2227, 2007.

[16] Z. Q. Sun, X. N. Han, H. J. Wang et al., "Prognostic significance of preoperative fibrinogen in patients with colon cancer," World Journal of Gastroenterology, vol. 20, no. 26, pp. 8583-8591, 2014.

[17] M. Najjar, S. Agrawal, J. Emond, and K. Halazun, "Pretreatment neutrophil-lymphocyte ratio: useful prognostic biomarker in hepatocellular carcinoma," Journal of Hepatocellular Carcinoma, vol. 5, pp. 17-28, 2018.

[18] H. Tang, W. Lu, B. Li, C. Li, Y. Xu, and J. Dong, "Prognostic significance of neutrophil-to-lymphocyte ratio in biliary tract cancers: a systematic review and meta-analysis," Oncotarget, vol. 8, no. 22, pp. 36857-36868, 2017.

[19] R. Z. Sharaiha, K. J. Halazun, F. Mirza et al., "Elevated preoperative neutrophil: lymphocyte ratio as a predictor of postoperative disease recurrence in esophageal cancer," Annals of Surgical Oncology, vol. 18, no. 12, pp. 3362-3369, 2011.

[20] Z. Wang, S. Peng, H. Xie et al., "Neutrophil-lymphocyte ratio is a predictor of prognosis in patients with castrationresistant prostate cancer: a meta-analysis," Cancer Management and Research, vol. 10, pp. 3599-3610, 2018.

[21] G. Absenger, J. Szkandera, M. Pichler et al., "A derived neutrophil to lymphocyte ratio predicts clinical outcome in stage II and III colon cancer patients," British Journal of Cancer, vol. 109, no. 2, pp. 395-400, 2013.

[22] T. Arigami, H. Okumura, M. Matsumoto et al., "Analysis of the fibrinogen and neutrophil-lymphocyte ratio in esophageal squamous cell carcinoma: a promising blood marker of tumor progression and prognosis," Medicine (Baltimore), vol. 94, no. 42, article e1702, 2015.

[23] T. Arigami, Y. Uenosono, D. Matsushita et al., "Combined fibrinogen concentration and neutrophil-lymphocyte ratio as a prognostic marker of gastric cancer," Oncology Letters, vol. 11, no. 2, pp. 1537-1544, 2016.
[24] T. Arigami, Y. Uenosono, S. Ishigami et al., "A novel scoring system based on fibrinogen and the neutrophil-lymphocyte ratio as a predictor of chemotherapy response and prognosis in patients with advanced gastric cancer," Oncology, vol. 90, no. 4, pp. 186-192, 2016.

[25] S. J. Fu, F. Ji, M. Han et al., "Prognostic value of combined preoperative fibrinogen and neutrophil-lymphocyte ratio in patients with hepatocellular carcinoma after liver transplantation," Oncotarget, vol. 8, no. 3, pp. 4301-4312, 2017.

[26] Y. Hao, X. Li, H. Chen et al., "A cumulative score based on preoperative neutrophil-lymphocyte ratio and fibrinogen in predicting overall survival of patients with glioblastoma multiforme," World Neurosurgery, vol. 128, pp. e427-e433, 2019.

[27] W. Huang, S. Wang, H. Zhang, B. Zhang, and C. Wang, "Prognostic significance of combined fibrinogen concentration and neutrophil-to-lymphocyte ratio in patients with resectable non-small cell lung cancer," Cancer Biology \& Medicine, vol. 15, no. 1, pp. 88-96, 2018.

[28] T. Kijima, T. Arigami, Y. Uchikado et al., "Combined fibrinogen and neutrophil-lymphocyte ratio as a prognostic marker of advanced esophageal squamous cell carcinoma," Cancer Science, vol. 108, no. 2, pp. 193-199, 2017.

[29] T. Kuwahara, H. Takahashi, D. Sano et al., "Fibrinogen and neutrophil-to-lymphocyte ratio predicts survival in patients with advanced hypopharyngeal squamous cell carcinoma," Anticancer Research, vol. 38, no. 9, pp. 5321-5330, 2018.

[30] X. Li, B. An, Q. Zhao et al., "Combined fibrinogen and neutrophil-lymphocyte ratio as a predictive factor in resectable colorectal adenocarcinoma," Cancer Management and Research, vol. 10, pp. 6285-6294, 2018.

[31] H. G. Liang, K. Gao, R. Jia, J. Li, and C. Wang, "Prognostic significance of the combination of preoperative fibrinogen and the neutrophil-lymphocyte ratio in patients with non-small cell lung cancer following surgical resection," Oncology Letters, vol. 17, no. 2, pp. 1435-1444, 2019.

[32] X. Liu, Z. Liu, E. Lin, Y. Chen, X. Sun, and Z. Zhou, “A cumulative score based on preoperative fibrinogen and the neutrophil-lymphocyte ratio to predict outcomes in resectable gastric cancer," Cancer Management and Research, vol. 10, pp. 3007-3014, 2018.

[33] C. Marchetti, A. Romito, A. Musella et al., "Combined plasma fibrinogen and neutrophil lymphocyte ratio in ovarian cancer prognosis may play a role?," International Journal of Gynecological Cancer, vol. 28, no. 5, pp. 939-944, 2018.

[34] H. Wang, J. Zhao, M. Zhang, L. Han, M. Wang, and L. Xingde, "The combination of plasma fibrinogen and neutrophil lymphocyte ratio (F-NLR) is a predictive factor in patients with resectable non small cell lung cancer," Journal of Cellular Physiology, vol. 28, no. 5, pp. 939-944, 2018.

[35] A. Stang, "Critical evaluation of the Newcastle-Ottawa scale for the assessment of the quality of nonrandomized studies in meta-analyses," European Journal of Epidemiology, vol. 233, no. 5, pp. 4216-4224, 2018.

[36] A. Sahni, P. J. Simpson-Haidaris, S. K. Sahni, G. G. Vaday, and C. W. Francis, "Fibrinogen synthesized by cancer cells augments the proliferative effect of fibroblast growth factor-2 (FGF-2)," Journal of Thrombosis and Haemostasis, vol. 6, no. 1, pp. 176-183, 2008.

[37] T. Yamaguchi, Y. Yamamoto, S. Yokota, M. Nakagawa, M. Ito, and T. Ogura, "Involvement of Interleukin-6 in the elevation of 
plasma fibrinogen levels in lung cancer patients," Japanese Journal of Clinical Oncology, vol. 28, no. 12, pp. 740-744, 1998.

[38] J. S. Palumbo, K. E. Talmage, J. V. Massari et al., "Platelets and fibrin(ogen) increase metastatic potential by impeding natural killer cell-mediated elimination of tumor cells," Blood, vol. 105, no. 1, pp. 178-185, 2005.

[39] J. S. Palumbo, K. W. Kombrinck, A. F. Drew et al., "Fibrinogen is an important determinant of the metastatic potential of circulating tumor cells," Blood, vol. 96, no. 10, pp. 3302-3309, 2000.

[40] P. E. Neagoe, A. Brkovic, F. Hajjar, and M. G. Sirois, "Expression and release of angiopoietin-1 from human neutrophils: intracellular mechanisms," Growth Factors, vol. 27, no. 6, pp. 335-344, 2009.

[41] A. D. Gregory and A. M. Houghton, "Tumor-associated neutrophils: new targets for cancer therapy," Cancer Research, vol. 71, no. 7, pp. 2411-2416, 2011.

[42] J. Cools-Lartigue, J. Spicer, B. McDonald et al., "Neutrophil extracellular traps sequester circulating tumor cells and promote metastasis," The Journal of Clinical Investigation, vol. 123, no. 8, pp. 3446-3458, 2013.

[43] J. J. Zhao, K. Pan, W. Wang et al., "The prognostic value of tumor-infiltrating neutrophils in gastric adenocarcinoma after resection," PLoS One, vol. 7, no. 3, article e33655, 2012.

[44] T. K. Offmann, G. D. Woracki, T. Tsukihiro et al., "Spontaneous apoptosis of circulating $\mathrm{T}$ lymphocytes in patients with head and neck cancer and its clinical importance," Clinical Cancer Research, vol. 8, no. 8, pp. 2553-2562, 2002.

[45] F. Shi, M. Shi, Z. Zeng et al., "PD-1 and PD-L1 upregulation promotes $\mathrm{CD} 8(+)$ T-cell apoptosis and postoperative recurrence in hepatocellular carcinoma patients," International Journal of Cancer, vol. 128, no. 4, pp. 887-896, 2011.

[46] E. S. Wu, T. Oduyebo, L. P. Cobb et al., "Lymphopenia and its association with survival in patients with locally advanced cervical cancer," Gynecologic Oncology, vol. 140, no. 1, pp. 76-82, 2016. 